\title{
Rehabilitation for Low Back Pain: A Narrative Review for Managing Pain and Improving Function in Acute and Chronic Conditions
}

Joseph V. Pergolizzi Jr. · Jo Ann LeQuang

Received: August 1, 2019 / Published online: January 31, 2020

(C) The Author(s) 2020

\section{ABSTRACT}

Low back pain (LBP) is prevalent and may transition into chronic LBP (cLBP) with associated reduced quality of life, pain, and disability. Because cLBP affects a heterogenous population, rehabilitation efforts must be individualized to meet the needs of various patient populations as well as individuals. This narrative review evaluated the many approaches to LBP rehabilitation including treatment-based classifications and specific types of rehabilitation efforts from exercise and physical therapy to spinal manipulation and bracing. Clinicians caring for patients with LBP or cLBP must be aware of the various options to find the right treatment course for each patient. In many cases, with proper patient expectations and care, nonpharmacological options may suffice to manage cLBP. While there is a rightful role for analgesics in the management of LBP, nonpharmacological options should be seriously considered, as they can play an important and health-sustaining role in patient management.

Keywords: Bracing; Chronic low back pain; Cognitive behavioral therapy; Kinesiology tape; Low back pain; Meditation; Orthotics; Physical therapy; Rehabilitation of low back pain; Spinal manipulation; Traction

Enhanced Digital Features To view enhanced digital features for this article go to https://doi.org/10.6084/ m9.figshare.11558706.

J. V. Pergolizzi Jr. · J. A. LeQuang ( $₫)$

NEMA Research, Inc, Naples, FL, USA

e-mail: joannlequang@gmail.com 


\section{Key Summary Points}

Low back pain (LBP) is a prevalent condition that affects a heterogenous population with varying degrees of duration (acute versus chronic), severity, pain intensity, and functional limitation. As such, treatments and rehabilitation efforts resist a one-size-fits-all approach.

Acute LBP may be treated conservatively at first and certain physical therapy approaches may exacerbate rather than help the condition; triage should be performed to identify patients who are likely going to require more complex and prolonged therapies compared to those whose back pain will resolve spontaneously.

Many rehabilitation techniques are available for chronic LBP and potential psychosocial factors that contribute to LBP (such as job dissatisfaction, anxiety, catastrophizing, depression, and so on) should be explored as well.

Physical therapy and exercise on a regular medically supervised program may reduce pain, improve function, and restore good balance, with Pilates and water exercises studied in this setting. The role of alternative practices (such as yoga and T'ai Chi) are less clear and the benefits of aerobic exercise in chronic LBP are equivocal.

Other rehabilitation treatments may include custom orthotics, bracing, hot or cold therapy, kinesiology tape, cognitive behavioral therapy, and patient education.

Traction may not be helpful in LBP patients, as it is associated with adverse events, including worsened pain, and has been eclipsed by newer, more promising rehabilitation strategies.

\section{INTRODUCTION}

Low back pain (LBP) is so prevalent globally that most people will experience at least one episode of it over their lifetime. The 1-year incidence of first-ever LBP has been estimated to be between 6.3 and $15.4 \%$, and the 1-year incidence of any episode of LBP range from 1.5 to $36 \%$ [1]. The majority of people who experience activitylimiting LBP have recurrences. The first incidence of LBP occurs most frequently in the third decade of life and prevalence increases until 65 years, whereupon the rate decreases [1].

Tertiary prevention of LBP aims at reducing the negative impact of pain, disability, and functional loss through rehabilitation [2]. The main goals of rehabilitation for LBP patients are to control pain, restore function, assure no future functional deficits occur, preserve employment and productivity, and in the case of acute LBP to prevent chronification [2]. The great challenge in LBP rehabilitation is the broad, heterogeneous population it affects, making it impossible to arrive at any basic general rehabilitation care paradigms that would apply to all or even most LBP subpopulations [3]. Numerous biological factors contribute to LBP, ranging from injury (disk herniation, trauma), structural deficits (spinal deformities), age- or occupation-related changes (nerve root compression, spinal stenosis), and even indirect biological factors such as obesity $[4,5]$, but psychological and social factors may play an unexpectedly large role in LBP in some patients. These factors include low educational status, stress, depression, anxiety, dissatisfaction with a job or work situation, and poor social support [1]. Recently, post-traumatic stress disorder (PTSD) was associated with incident chronic LBP (cLBP) [6].

LBP may be treated with pharmacological therapy, surgical interventions, or rehabilitation, which we are defining to include physical therapy, exercise, spinal manipulation, and other practices. Combination therapy and interdisciplinary approaches to LBP are considered helpful in many cases. The goal of this narrative review is to present rehabilitation strategies for patients suffering from acute or 
chronic LBP. This article is based on previously conducted studies and does not contain any studies with human participants or animals performed by any of the authors.

\section{METHODS}

The authors sought to create a succinct narrative review of rehabilitation in the setting of LBP and conducted a literature search using the PubMed database in May 2019 for "rehabilitation low back pain." The bibliographies of particularly relevant articles were searched as well. Since studies were few and involved different therapies, a systematic review or meta-analysis was not possible.

\section{RESULTS}

\section{Diagnosis of LBP}

The numerous forms of LBP make diagnosis challenging. Acute LBP is new-onset LBP of short duration, often from an identifiable cause such as an injury. Nonspecific LBP (which may also be acute) has no known anatomical cause. The anticipated trajectory of acute LBP is several days or weeks of pain and limited function as the underlying injury or tissue damage heals. LBP is often described in temporal terms: acute LBP is pain that persists less than 4 weeks, subacute LBP lasts more than four but less than 12 weeks, and cLBP is defined as pain that lasts more than 12 weeks. These temporal delimiters are far from clear-cut. A less systematic (but arguably more realistic) paradigm states that, for some individuals, LBP may be episodic, characterized by remissions and relapses with periodic flares [7]. Such LBP might be described as persistent LBP. For the purposes of this narrative review, persistent LBP will be considered as a type of cLBP. The transition of acute LBP to cLBP involves central sensitization or windup, an aberrant neurological process [2].

The first step in diagnosing cLBP must be to evaluate the possibility of a neuropathic component to the pain [8]. Chronic lumbar radicular pain is the most common neuropathic pain syndrome associated with cLBP and affects about $20-35 \%$ of patients with cLBP [9]. Neuropathic LBP is associated with greater pain intensity, greater disability, more anxiety and depression, and a lower quality of life than nociceptive (non-neuropathic) LBP $[10,11]$. Neuropathic cLBP occurs when a peripheral or central lesion or nervous system disorder are present and identifiable and that pain is distributed and described in such a way that a neuropathic pain syndrome is plausible. For example, diffuse, widespread pain is generally not considered a plausible form of neuropathic pain. Lumbosacral radiculopathy (LSR) is a common musculoskeletal condition associated with LBP [12]. Magnetic resonance imaging (MRI) is considered the optimal tool for diagnosing LSR, although it is not always available or cost effective for routine examinations [13]. Yet, the neuropathic component of LBP cannot be captured in imaging. An assessment tool for neuropathic pain is the Self-Reported Leeds Assessment of Neuropathic Symptoms and Signs (S-LANSS) [14, 15]. A clinical neurological examination can also help identify neurologic pain sites. Other diagnostic tools for all forms of LBP include pain assessments, pain descriptions, pinpointing pain sites (which can be done on a drawing outlining the human body), the patient's medical history, and interviews with the patient.

\section{Treatment of Acute LBP}

Patients complaining of acute LBP often consult with healthcare professionals but there are limited data supporting the value of one particular treatment over another in terms of preventing the possible transition of acute LBP to cLBP. An acute episode of LBP may be treated with manual therapy and low-impact exercise. Nonpharmacological approaches and avoidance of surgical interventions are preferred at this stage $[16,17]$. In some cases, a short course of nonopioid analgesics, such as nonsteroidal antiinflammatory drugs (NSAIDs), may be used.

A risk stratification system has been designed known as the STarT Back Screening Test (STarT Back) to help identify acute LBP patients at 
elevated risk for developing more persistent symptoms of LBP [18]. Among these risk factors are high levels of perceived pain, mood disturbances, catastrophizing, and fear-avoidance behaviors [19]. Such higher-risk patients may be treated with physical therapy, behavioral interventions, and other means to manage some psychological factors that may impede recovery. A new approach called psychologically informed physical therapy (PIPT) blends physical therapy with cognitive therapy to prevent LBP chronification [20].

The stepped care paradigm holds that acute LBP is first treated conservatively and with the more inexpensive interventions but advances to more complex and expensive treatments as needed. Some pathologies are "red flags" and necessitate specific interventions but otherwise patients are treated with conservative therapy, patient education, and reassurance. Physical therapy or other techniques are not considered appropriate for all patients and, indeed, may have adverse effects in certain patients. For that reason, physical therapy is not something that should be used too quickly for the care of acute LBP. The underlying premise is that many people with acute LBP will recover with minimal suffering, limited effort, and conservative care; those with more severe forms of LBP are likely to have no adverse consequences from waiting through a period of conservative intervention before more aggressive treatments begin [21].

Stratified care attempts to triage patients with acute LBP and identify those who are likely going to require more complex treatment and to advance them into appropriate therapy without having to wait [21]. Risk stratification tools exist to help identify patients with specific biopsychosocial risk factors and clinical trials evaluating their use are ongoing. If acute or subacute LBP transitions to CLBP, rehabilitation efforts should be considered.

In this context, clinicians must be aware that acute LBP may transition into cLBP and bring with it decreased function, increased pain, and disability. Rehabilitation following acute low back pain can be crucial to prevent chronification and avoid future pain. These efforts include exercise, physical training, and educational efforts [2]. Thus, it is important to diagnose acute LBP, identify patients at risk for cLBP, and introduce rehabilitation early-but not too early.

\section{Treatment-Based Classifications for Rehabilitation}

Rehabilitation efforts may be selected based on a patient-centric model, which views the patient and his or her needs holistically and takes into account the multiple factors that may be involved in cLBP. Treatment-based classification (TBC) attempts to triage the care for patients with LBP by grouping them at the first level (first contact with a healthcare provider for acute LBP) or second level (in rehabilitation) [3]. The goal of level one is to determine if the patient is a candidate for rehabilitation. In order to make this determination, serious underlying pathologies and comorbidities are to be ruled out so an assessment can be made as to whether the patient would be appropriate for self-care. See Table 1.

Rehabilitation for LBP is itself a complex subject, as there are many forms of rehabilitation and the clinician may need to guide the patient to the most appropriate rehabilitation program(s). According to the TBC paradigm, there are three main categories of rehabilitation: symptomatic, movement control, and a functional approach. Symptomatic care is for new or recurrent episodes of LBP with strong symptomatic features. Movement control is appropriate for patients with moderate pain and disability. The functional approach is appropriate for patients with mild LBP and disability and aims to alleviate functional deficits [3]. Many patients seem to defy classification using the TBC model; they tend to be older individuals (odds ratio or OR 1.01, 95\% confidence interval or CI 1.003-1.033), with LBP for a longer duration (OR 1.001, 95\% CI 1.000-1.001), prior history of LBP (OR 1.61, 95\% CI 1.04-2.49), fewer fear-avoidance beliefs related to work (OR $0.98,95 \%$ CI $0.96-0.99$ ) and to physical activity (OR 0.98, 95\% CI 0.96-0.996) and having less severe disability associated with LBP (OR 0.98, 95\% CI 0.96-0.99). It appears that those with less clear-cut classification of LBP are less 
Table 1 Characteristics of patients with LBP and rehabilitation options [3]

\begin{tabular}{|c|c|c|}
\hline Characteristic & $\begin{array}{l}\text { Is rehabilitation } \\
\text { appropriate? }\end{array}$ & Issues with rehabilitation \\
\hline \multicolumn{3}{|l|}{ Comorbidities } \\
\hline $\begin{array}{l}\text { Severe comorbidities that would impede } \\
\text { or preclude rehabilitation efforts }\end{array}$ & No & May be suitable for medical management \\
\hline Moderate comorbidities & Maybe & Comorbidity cannot interfere with rehabilitation efforts \\
\hline Mild comorbidities & Yes & \\
\hline Controlled comorbidities & Maybe & $\begin{array}{l}\text { Comorbid conditions that can be well managed likely would } \\
\text { not stop rehabilitation efforts }\end{array}$ \\
\hline \multicolumn{3}{|l|}{ Leg pain } \\
\hline $\begin{array}{l}\text { Leg pain with progressive neurological } \\
\text { deficits }\end{array}$ & No & May be suitable for medical management \\
\hline Prominent leg pain & Maybe & $\begin{array}{l}\text { If the patient has low psychosocial risks, rehabilitation may } \\
\text { be appropriate. If the patient has high or moderate } \\
\text { psychosocial risks, rehabilitation may not be appropriate }\end{array}$ \\
\hline \multicolumn{3}{|l|}{ Psychosocial risks } \\
\hline Medium or high psychosocial risk & Maybe & $\begin{array}{l}\text { Higher-risk patients may be less compliant or unwilling to } \\
\text { participate }\end{array}$ \\
\hline Low psychological risk & Yes & Patient may also be appropriate for self-care regimen \\
\hline \multicolumn{3}{|l|}{ Type of $L B P$} \\
\hline Axial & Maybe & Self-care might also be an option \\
\hline \multicolumn{3}{|l|}{ Pain intensity levels } \\
\hline Mild to none & Yes & Self-care might also be an option \\
\hline Mild to moderate & Yes & \\
\hline Moderate to severe & Maybe & This may change if pain intensity can be better controlled \\
\hline Severe to very severe & No & \\
\hline
\end{tabular}

adversely impacted by it (less disability, fewer fear-avoidance beliefs) although they tend to have LBP for a protracted period of time [22].

A few potential pitfalls should be mentioned as the clinical team and patient embark on a rehabilitation plan. Clinicians must be sure to take into account the potential psychosocial factors that may contribute to LBP, such as anxiety, job dissatisfaction, catastrophizing beliefs, and depression. In some cases, referral to a psychologist or psychiatrist may be appropriate. Second, the patient's LBP and overall condition is dynamic and changes, partly as a result of the rehabilitation, and these changes must be accommodated moving forward with rehabilitation. Finally, it must be mentioned that some patients with LBP require no medical intervention and their LBP will resolve spontaneously [3].

Finding the right rehabilitation program can be daunting, because multiple classification systems for LBP exist with corresponding 
strengths and limitations. Billis et al. [23] looked at systems across nine countries and came back with 39 different classification systems, most of which relied on a biomedical paradigm. Biomedical assessment is important, but it is limited in terms of how well it can distinguish among subgroups of patients. Therefore, it is generally accepted that a good classification system goes beyond pathoanatomical causes of back pain toward a system that reviews signs and symptoms.

Delitto et al. [24] published their TBC system that grouped patients by how well they responded to specific categories of treatment. For instance, patients were grouped by those who responded best to: direction-specific exercises, manipulation, stabilization exercises, and traction. The Delitto system has been utilized and refined over the years $[25,26]$. Since some patients could fit into more than one of the subgroups, a modification proposed an ordered categorization such that patients are ranked by those who respond to directional exercises first, then manipulation, and finally stabilization in that order; if a patient responded to multiple categories, the first one was defining. This revised method deleted traction from the list and favored direction-specific exercises; it also prevented patients from being assigned to more than one group [27]. While Delitto's TBC paradigm is helpful, evidence for its effectiveness is mixed. A randomized controlled trial to evaluate the effectiveness of Delitto's classificationbased treatment algorithm found it was not effective in improving physical care outcomes in patients with subacute LBP or cLBP [28].

An early metric for LBP was developed by Waddell et al. in 1980. The Waddell score was based on eight nonorganic or behavioral signs to evaluate illness behavior in LBP patients. The metric has been controversial in that it is not established to be a valid screening tool for measuring psychological distress, although it measures pain intensity and functional limitations. In a study of 20 hypotheses about the Waddell score in LBP that were then tested in a sample of 229 cLBP patients at a single outpatient rehabilitation center, it was found that the Waddell score had $100 \%$ confirmation for pain, $80 \%$ for physical aspects, $80 \%$ for illness behavior, and 50\% for psychological aspects [29]. In a study of 75 consecutive patents with cLBP, 64\% had no Waddel signs at all [30]. However, a prospective study of cLBP patients found $53 \%$ of patients had some relevant psychological disturbance, the treatment of which might improve the outcome of their cLBP [31].

Among the rehabilitative efforts for cLBP are physical therapy (directional preference exercise, sensorimotor exercises, stabilization exercises, flexibility exercises, strength and conditioning exercises, aerobics, and general fitness exercises), spinal manipulation, occupational therapy or work- and sport-specific exercises, cognitive behavioral therapy, mindfulness meditation, orthotics, bracing, hot or cold therapy, kinesiology tape, patient education, traction, and rest [3].

\section{TYPES OF REHABILITATION}

\section{Physical Therapy and Exercise}

Exercise is considered to be ineffective for acute LBP, but may be effective for patients with subacute LBP or cLBP [32]. Physical therapy for cLBP has been divided into four major classification systems that attempt to find the most appropriate therapeutic course for a given subpopulation of patients. Approaches are mechanical (based on directional preferences) [33], a movement-systems approach, a mechanistic method [34], and treatment-based classification (TBC). Strength-building exercises, which aim at building up support of the spine, may be recommended; an added benefit of such exercises is that they may improve posture and endurance.

The McKenzie method [35] involves repeated movements or sustained positions which are accompanied by manual overpressure or mobilization by a trained therapist. McKenzie therapists undergo specific training at the McKenzie Institute International [36]. In a head-to-head clinical trial of 260 LBP patients (at least 8 weeks of symptoms, $85 \%$ had $>12$ weeks), at 2 and 8 months, intensive strength training and McKenzie patients had similar results in terms of pain relief and disability. McKenzie patients 
showed a significant reduction in pain at 2 months $(p=0.01)$ but no significant difference at 8 months [37]. A new treatment model combines McKenzie exercises with muscular energy techniques [38].

Directional preference exercises provide to LBP patients rapid and durable pain relief after performing repeated lumbar flexions, extensions, side glide exercises, and rotations. These exercises can be performed in the patient's preferred direction or in the opposite direction. In a study of 312 acute, subacute, and chronic LBP patients, $74 \%$ responded to directional preference exercises which had significantly greater improvements in all outcomes and a three-fold decrease in medication use [39].

A regular program of physical exercise has been shown to reduce pain, reduce disability, and improve balance in cLBP patients $[40,41]$. Physical activity has other positive benefits as well [42]. The challenge with cLBP is to identify the most appropriate types of physical exercise. Pilates exercises are based on the principles of concentration, control, flow of movement, and breathing technique [43] and is sometimes recommended for patients with cLBP. A systematic review and other studies reported that Pilates was more effective at reducing pain and disability in people with cLBP compared to standard care (usual care or an educational booklet about back pain) on a short- or medium-term basis [44-46]. For long-term benefits, Pilates was similar to cycling or McKenzie exercises [44].

Aerobic exercise has established benefits for overall well-being, fitness, and cardiovascular health [47] but its role for the treatment of patients with cLBP is unclear. In a study of 46 patients with cLBP, patients were randomized and asked to perform deep-water running three times a week for 15 weeks. Deep-water running involves "running" in shoulder-high water at the individual's aerobic threshold. All patients received physical therapy (individualized land exercises), manual therapy, back care, patient education, and lifestyle advice but the active group received three weekly 20 -min sessions of deep-water running. Both groups of patients had significant improvements versus baseline but the patients who added deep-water running had significantly reduced pain intensity compared to the patients who did not perform the deep-water running [48].

Stabilization exercises, which aim to increase core body strength, enhance neuromuscular control, and promote endurance, were shown in an unblinded clinical study to provide more functional improvements to people with cLBP than yoga, but yoga provided better pain control [49]. A novel program combining traditional yoga with stabilization exercises has been described in the literature; this program was created to decrease back pain, restore spinal function, and strengthen the musculature that supports and stabilizes the spine [50].

Qigong exercise is a traditional Chinese practice that combines specific slow flowing body movements with meditation with the goal of consolidating attention, regulating breathing, and transitioning smoothly from static to dynamic postures [51]. Although not widely practiced in the US, it has been evaluated in China in 72 office workers with chronic nonspecific LBP and it was found to significantly reduce pain levels and functional disability compared to placebo (no intervention). Participants in the Qigong group practiced every day at work for $1 \mathrm{~h}$ and also at home for 6 weeks [52]. Tai Chi, a Chinese mindfulness technique involving slow, controlled movements with regulated breathing has also been found in a systematic review to reduce symptoms of cLBP $[53,54]$.

Yoga was evaluated in a systematic review and meta-analysis in 12 studies $(n=1080$ cLBP patients) and it was reported with "low to moderate certainty" that yoga improved back function at three and 6 months compared to no exercise. Yoga may also reduce pain, but improvement is modest [55].

Badaunjin is an exercise system from China which has been studied for the treatment of cLBP. Badaunjin is composed of eight discreet, smooth, easy-to-execute movements that are performed in a specific, mindful sequence with careful attention to breathing [56]. A systematic review of nine studies ( $n=519$ cLBP patients) suggested Badaunjin was effective in treating cLBP in terms of reducing pain and disability and also found it may work well in combination with other therapies [56]. 


\section{Spinal Manipulation}

Both chiropractors and manual therapists use spinal manipulation as a treatment for LBP. In Holland, a small group of physicians has been trained in musculoskeletal medicine and this group has been recognized in the healthcare system for their specific expertise. The musculoskeletal therapy they offer involves spinal manipulation, orthopedics, neurology, radiology, and the medico-legal aspects of musculoskeletal disorders. In a survey from Holland among these specialists, 90 physicians responded and said they treated mostly cLBP $(48.1 \%$ of patients) with symptoms that had lasted over a year (62.1\%) and cLBP patients had a mean pain intensity score of 6.0 on the numerical rating scale. The majority of patients treated by these physicians had previously been treated by a physical therapist (68.1\%) [57]. The role of such specialized groups of healthcare providers remains to be defined in the future.

\section{Cognitive Behavioral Therapy}

Cognitive behavioral therapy (CBT) can be effective in reducing pain, improving daily function, and improving quality of life in patients with cLBP. Unlike exercise programs or physical therapy, CBT addresses the psychosocial contributors to cLBP. A recent series of structured interviews in a prospective extended cohort ( $n=277,85 \%$ response rate) found positive 1-year response rates that were maintained at 5 years of follow-up [58]. A postmarketing study found positive responses to an intensive 2-week course of CBT in cLBP patients were durable at 2 years and patients reported less consumption of analgesics [59].

Like other interventions, compliance can be an issue with CBT. In a study of 290 patients with cLBP from a single Veterans Health Affairs (VHA) center, $54 \%$ of patients declined to participate in CBT when it was offered to them. Regression analysis showed that individuals prescribed an opioid were more likely to decline CBT than those not prescribed opioids. This particular study suggests that patients administered an opioid analgesic were less engaged in their treatment [60]. Of those who enrolled in $\mathrm{CBT}$, retention rates were good.

Combining CBT with physical therapy interventions was shown in a systematic review to reduce pain and disability in patients with cLBP and to improve their quality of life, but CBT conferred no additional benefit over physical therapy alone in reducing depression associated with cLBP [61]. In a systematic review and meta-analysis, combined forms of CBT plus progressive relaxation techniques can be more effective than placebo (waiting list control) for short-term pain relief in cLBP but it is not clear if these results are durable $[62,63]$. A meta-review and analysis (40 studies, 6858 patients with cLBP of $>1$ year who had often failed other treatments) found biopsychosocial rehabilitation was more effective than usual care in terms of controlling pain and decreasing disability [64].

\section{Mindfulness Meditation}

Mindfulness meditation (without exercise) was evaluated in a pilot study among older adults with cLBP. After 8 weeks, it was determined that mindfulness meditation initiatives are feasible in this population and may lead to improvements in pain acceptance as well as improvements in physical function [65]. Progressive muscle relaxation techniques, in which participants are encouraged to relax, become mindful of various body parts, and consciously try to relax these body areas, was found to improve pain better than placebo in patients with cLBP with mild pain [66]. Although this technique must be learned or can be led by an individual talking patients through it, it may eventually be practiced at home alone once the patient masters it.

\section{Custom Orthotics}

A study of 225 adults with symptomatic LBP for 3 months or less duration were randomized into three groups: one group received custom-made shoe orthotic devices (orthotic group), the second group received orthotics plus chiropractic manipulation of the spine, hot or cold therapy, 
and manual massage (plus group), and the third group received no special care (waitlist). At 6 weeks, all three groups reported significant improvement in average back pain against baseline but only the orthotic and plus groups showed functional improvement as well. Compared to waitlist patients, the orthotic patients showed significant pain reduction $(p<0.0001)$ and functional improvement $(p=0.0068)$. The plus group showed a significant improvement in function $(p=0.0278)$ compared to orthotics alone but pain scores remained similar. At 12 weeks and beyond, scores were similar among all three groups [67].

\section{Bracing}

In a study of 20 adult women with back pain secondary to idiopathic scoliosis, it was found that back braces (worn at least $2 \mathrm{~h}$ a day) resulted in significant improvements in worst pain, back pain, and leg pain (7.15-5.85; 6.55-5.25; $5.65-3.55$, respectively, $p<0.05)$. No changes in quality of life were reported [68]. Results from a retrospective observational study of 174 patients with cLBP associated with Modic type 1 changes wore a rigid lumbar brace for 3 months; the brace was withdrawn gradually at 3 months. Pain improved by at least $30 \%$ in 3 months in $79 \%$ of the braced patients and 2 months after the brace was withdrawn, pain recurred in $65 \%$ [69]. While scoliosis patients may be indicated for bracing, it is not established if bracing is beneficial in patients with mechanical cLBP or other such painful conditions [70].

\section{Hot and Cold Therapy}

In a systematic review and meta-analysis, nine clinical studies ( $n=1117$ LBP patients) found that heat wraps significantly reduced pain in acute and subacute LBP compared to placebo and found overall limited evidence that superficial application of hot or cold packs could improve the pain associated with LBP, but further study is needed, particularly with respect to cLBP [71].

\section{Kinesiology Tape}

Kinesiology tape, also called balance tape, can be used to reduce acute nonspecific LBP due to repeated lifting. Tape is applied daily and left on during waking hours (about $16 \mathrm{~h}$ a day) and can be used for several consecutive days [72]. Kinesiology tape was evaluated in 44 patients with nonspecific cLBP in a placebo-controlled trial (placebo patients received "placebo taping"). Kinesiology tape patients experienced a significant decrease in pain compared to placebo patients at the second week of the study which they maintained through week 4 . The experimental group also had improvements in their disability (significant at week 4) and trunk flexion range of motion improvements (significant at week 2) [73]. A systematic review of five studies $(n=306)$ found that kinesiology taping was effective as an adjunctive but not as monotherapy for cLBP, particularly in terms of improving range of motion [74].

\section{Patient Education}

In a study of 202 individuals with acute LBP ( $<6$ weeks) and considered to be at risk for developing cLBP, all patients received usual care and two 1-h educational sessions. Patients were randomized to receive either patient education (pain information, self-management techniques, understanding biopsychosocial contributors to LBP) or placebo education (active listening without advice or information). Adding this educational component to care did not improve pain outcomes and the educational sessions had a similar effect as placebo [75].

\section{Traction}

Mechanical and manual traction are old forms of rehabilitation therapy for LBP that have been falling out of favor as new treatments emerge. In a systematic review and meta-analysis (32 randomized controlled trials, $n=2762$ ) traction was found to have little effect on pain intensity, function, global improvement, or ability to return to work for patients with LBP. Adverse events for traction can include worsened pain, 
neurological symptoms, and subsequent surgery [76]. It has been theorized that one reason for the relatively poor clinical results from traction reported in the literature may be due to the fact that there are multiple different types of traction and parameter settings and it is used in a range of patients with back problems [3]. Nevertheless, traction is not frequently considered as a treatment for cLBP today.

\section{Rest}

Bed rest was once a frequent recommendation for patients complaining about back pain, but today most clinicians favor early activity and exercise over rest. Physical therapy and specific exercises are recommended by many clinicians, with or without pharmacological therapy [35].

\section{DISCUSSION}

Patient expectations appear to play a role in treatment outcomes. In a study of 593 chiropractic patients, those who expected improvements were $58 \%$ more likely to report an improved condition by their fourth visit (relative risk 1.48, 95\% confidence interval 1.28-1.95) compared to those who did not expect good results [77]. Biopsychosocial interventions for LBP were found to be more effective than education/advice for LBP patients. The most effective forms of biopsychosocial interventions were those that focused on psychosocial factors (understanding the nature of pain, coping skills, goal setting, and pushing aside unhelpful thoughts) [78]. Incorporating biopsychosocial aspects to physiotherapy is recognized as being important but there are limited guidelines to encourage how this can be integrated in clinical practice [79].

In a systematic review of nonpharmacological treatments for CLBP, four types of treatments were evaluated in 12 randomized clinical trials: total disk replacement, fusion, cognitive behavioral therapy, and physical therapy. Each of these four treatments conferred specific benefits and no treatment was devoid of benefits. However, reviewers could not make clearcut statements as to which treatment was best for cLBP [80]. Studies suggest that surgical procedures offer the best outcomes in terms of improved function and reduced pain when compared to rehabilitation, but sometimes the difference is modest and it is unclear if specific patient populations might respond differently [81]. In other words, not every cLBP is a suitable candidate for surgery-or for rehabilitation. Individualized care and shared decisionmaking paradigms may lead to different choices for similar patients.

\section{CONCLUSIONS}

Chronic LBP is a prevalent and surprisingly complex condition that may respond to a range of nonpharmacological treatments. The difficulty in rehabilitation for cLBP is the fact that patient populations are heterogeneous and individualized therapy is appropriate. Physical and occupational therapy as well as other forms of exercise can be valuable; many patients derive benefit from cognitive behavioral therapy as cLBP has a psychosocial dimension as well. Further, cLBP is a dynamic condition that may require changes in therapeutic approach over time.

\section{ACKNOWLEDGEMENTS}

Funding. No funding or sponsorship was received for this study or publication of this article.

Authorship. Both authors meet the International Committee of Medical Journal Editors (ICMJE) criteria for authorship for this article, take responsibility for the integrity of the work as a whole, and have given their approval for this version to be published.

Disclosures. Joseph V. Pergolizzi, Jr. is a member of the journal's Editorial Board. Jo Ann LeQuang has nothing to disclose.

Compliance with Ethics Guidelines. This article is based on previously conducted studies 
and does not contain any studies with human participants or animals performed by any of the authors.

Open Access. This article is distributed under the terms of the Creative Commons Attribution-NonCommercial 4.0 International License (http://creativecommons.org/licenses/ by-nc/4.0/), which permits any noncommercial use, distribution, and reproduction in any medium, provided you give appropriate credit to the original author(s) and the source, provide a link to the Creative Commons license, and indicate if changes were made.

\section{REFERENCES}

1. Hoy D, Brooks P, Blyth F, Buchbinder R. The epidemiology of low back pain. Best Pract Res Clin Rheumatol. 2010;24(6):769-81.

2. Dorner TE, Crevenna R. Preventive aspects regarding back pain. Wiener medizinische Wochenschrift (1946). 2016;166(1-2):15-21.

3. Alrwaily M, Timko M, Schneider M, et al. Treatment-based classification system for low back pain: revision and update. Phys Ther. 2016;96(7): 1057-66.

4. Kikuchi S. New concept for backache: biopsychosocial pain syndrome. Eur Spine J. 2008;17(Suppl 4):421-7.

5. Shiri R, Karppinen J, Leino-Arjas P, Solovieva S, Viikari-Juntura E. The association between obesity and low back pain: a meta-analysis. Am J Epidemiol. 2010;171(2):135-54.

6. Suri P, Boyko EJ, Smith NL, et al. Post-traumatic stress disorder symptoms are associated with incident chronic back pain: a longitudinal twin study of older male veterans. Spine. 2019;44:1220-7.

7. Croft PR, Macfarlane GJ, Papageorgiou AC, Thomas E, Silman AJ. Outcome of low back pain in general practice: a prospective study. BMJ (Clin Res Ed). 1998;316(7141):1356-9.

8. Nijs J, Apeldoorn A, Hallegraeff $\mathrm{H}$, et al. Low back pain: guidelines for the clinical classification of predominant neuropathic, nociceptive, or central sensitization pain. Pain Phys. 2015;18(3):E333-46.
9. Freynhagen R, Baron R. The evaluation of neuropathic components in low back pain. Curr Pain Headache Rep. 2009;13:185-90.

10. Smart K, Blake C, Staines A, Doody C. Self-reported pain severity, quality of life, disability, anxiety and depression in patients classified with 'nociceptive', 'peripheral neuropathic' ad 'central senstisation' pain. The discriminant validity of mechanismsbased classifications of low back $( \pm$ leg) pain. Man Ther. 2012;17:119-25.

11. Beith I, Kemp A, Kenyon J, Prout M, Chestnut T. Identifying neuropathic back and leg pain: a crosssectional study. Pain. 2011;152:1511-6.

12. Tawa N, Diener I, Louw Q, Rhoda A. Correlation of the self-reported Leeds assessment of neuropathic symptoms and signs score, clinical neurological examination and MR imaging in patients with lumbo-sacral radiculopathy. BMC Neurol. 2019;19(1):107.

13. Bertilson B, Brosjo E, Strender L. Assessment of nerve involvement in the lumbar spine: agreement between magnetic resonance imaging, physical examination and pain drawing findings. BMC Musculoskelet Disord. 2019;11:202.

14. Scharfer A, Hall T, Briffa K. Classification of low back-related leg pain-a proposed patho-mechanismbased approach. Man Ther. 2007;14(2):222-30.

15. Capra F, Valti C, Donati R. Validity of the straightleg raise test for patients with sciatic pain with or without lumbar pain using magnetic resonance imaging results as a reference standard. J Man Phys Ther. 2011;34:231-8.

16. Kosloff TM, Elton D, Shulman SA, Clarke JL, Skoufalos A, Solis A. Conservative spine care: opportunities to improve the quality and value of care. Popul Health Manag. 2013;16(6):390-6.

17. Chou R, Deyo R, Friedly J, et al. Nonpharmacologic therapies for low back pain: a systematic review for an American College of Physicians Clinical Practice guideline. Ann Intern Med. 2017;166(7):493-505.

18. Hill JC, Dunn KM, Lewis M, et al. A primary care back pain screening tool: identifying patient subgroups for initial treatment. Arthritis Rheum. 2008;59(5):632-41.

19. Delitto A, Patterson CG, Stevans JM, et al. Study protocol for targeted interventions to prevent chronic low back pain in high-risk patients: a multisite pragmatic cluster randomized controlled trial (TARGET Trial). Contemp Clin Trials. 2019;82: 66-76. 
20. Nicholas MK, George SZ. Psychologically informed interventions for low back pain: an update for physical therapists. Phys Ther. 2011;91(5):765-76.

21. Linton SJ, Nicholas $M$, Shaw W. Why wait to address high-risk cases of acute low back pain? A comparison of stepped, stratified, and matched care. Pain. 2018;159(12):2437-41.

22. Stanton TR, Hancock MJ, Apeldoorn AT, Wand BM, Fritz JM. What characterizes people who have an unclear classification using a treatment-based classification algorithm for low back pain? A cross-sectional study. Phys Ther. 2013;93(3):345-55.

23. Billis EV, McCarthy CJ, Oldham JA. Subclassification of low back pain: a cross-country comparison. Eur Spine J. 2007;16(7):865-79.

24. Delitto A, Erhard RE, Bowling RW. A treatmentbased classification approach to low back syndrome: identifying and staging patients for conservative treatment. Phys Ther. 1995;75(6):470-85 (discussion 485-479).

25. Fritz JM, Cleland JA, Childs JD. Subgrouping patients with low back pain: evolution of a classification approach to physical therapy. J Orthop Sports Phys Ther. 2007;37(6):290-302.

26. Stanton TR, Fritz JM, Hancock MJ, et al. Evaluation of a treatment-based classification algorithm for low back pain: a cross-sectional study. Phys Ther. 2011;91(4):496-509.

27. Fritz JM, Brennan GP, Clifford SN, Hunter SJ, Thackeray A. An examination of the reliability of a classification algorithm for subgrouping patients with low back pain. Spine. 2006;31(1):77-82.

28. Apeldoorn AT, Ostelo RW, van Helvoirt H, et al. A randomized controlled trial on the effectiveness of a classification-based system for subacute and chronic low back pain. Spine. 2012;37(16):1347-56.

29. Apeldoorn AT, Ostelo RW, Fritz JM, van der Ploeg T, van Tulder MW, de Vet HC. The cross-sectional construct validity of the Waddell score. Clin J Pain. 2012;28(4):309-17.

30. Novy DM, Collins HS, Nelson DV, et al. Waddell signs: distributional properties and correlates. Arch Phys Med Rehabil. 1998;79(7):820-2.

31. Apeldoorn AT, Bosselaar H, Ostelo RW, et al. Identification of patients with chronic low back pain who might benefit from additional psychological assessment. Clin J Pain. 2012;28(1):23-31.

32. Faas A. Exercises: which ones are worth trying, for which patients, and when? Spine. 1996;21(24): 2874-8 (discussion 2878-2879).
33. Hefford C. McKenzie classification of mechanical spinal pain: profile of syndromes and directions of preference. Man Ther. 2008;13(1):75-81.

34. O'Sullivan P. Diagnosis and classification of chronic low back pain disorders: maladaptive movement and motor control impairments as underlying mechanism. Man Ther. 2005;10(4):242-55.

35. Battie M, Cherkin D, Dunn R, Ciol M, Wheeler K. Managing low back pain: attitudes and treatment preferences of physical therapists. Phys Ther. 1994;74(3):219.

36. Mann SJ, Singh P. McKenzie back exercises. In: StatPearls. Treasure Island: StatPearls Publishing; 2019.

37. Petersen T, Kryger P, Ekdahl C, Olsen S, Jacobsen S. The effect of McKenzie therapy as compared with that of intensive strengthening training for the treatment of patients with subacute or chronic low back pain: a randomized controlled trial. Spine. 2002;27(16):1702-9.

38. Szulc P, Wendt M, Waszak M, Tomczak M, Cieslik $\mathrm{K}$, Trzaska T. Impact of McKenzie method therapy enriched by muscular energy techniques on subjective and objective parameters related to spine function in patients with chronic low back pain. Med Sci Monit Int Med J Exp Clin Res. 2015;21: 2918-32.

39. Long A, Donelson R, Fung T. Does it matter which exercise? A randomized control trial of exercise for low back pain. Spine. 2004;29(23):2593-602.

40. Airaksinen O, Brox JI, Cedraschi C, et al. Chapter 4. European guidelines for the management of chronic nonspecific low back pain. Eur Spine J. 2006;15(Suppl 2):S192-300.

41. Howe TE, Rochester L, Neil F, Skelton DA, Ballinger C. Exercise for improving balance in older people. Cochrane Database Syst Rev. 2011;11:CD004963.

42. Chodzko-Zajko WJ, Proctor DN, Fiatarone Singh MA, et al. American College of Sports Medicine position stand. Exercise and physical activity for older adults. Med Sci Sports Exerc. 2009;41(7): 1510-30.

43. Di Lorenzo CE. Pilates: what is it? Should it be used in rehabilitation? Sports Health. 2011;3(4):352-61.

44. Yamato TP, Maher CG, Saragiotto BT, et al. Pilates for low back pain. Cochrane Database Syst Rev. 2015;7:CD010265.

45. Lin HT, Hung WC, Hung JL, Wu PS, Liaw LJ, Chang JH. Effects of Pilates on patients with chronic non- 
specific low back pain: a systematic review. J Phys Ther Sci. 2016;28(10):2961-9.

46. Patti A, Bianco A, Paoli A, et al. Effects of Pilates exercise programs in people with chronic low back pain: a systematic review. Medicine. 2015;94(4): e383.

47. Fang N, Jiang M, Fan Y. Association between psoriasis and subclinical atherosclerosis: a meta-analysis. Medicine. 2016;95(20):e3576.

48. Cuesta-Vargas AI, Garcia-Romero JC, Arroyo-Morales M, Diego-Acosta AM, Daly DJ. Exercise, manual therapy, and education with or without highintensity deep-water running for nonspecific chronic low back pain: a pragmatic randomized controlled trial. Am J Phys Med Rehabil. 2011;90(7): 526-34 (quiz 535-528).

49. Demirel A, Oz M, Ozel YA, Cetin H, Ulger O. Stabilization exercise versus yoga exercise in nonspecific low back pain: pain, disability, quality of life, performance: a randomized controlled trial. Complementary Ther Clin Pract. 2019;35:102-8.

50. Barr K, Griggs M, Cadby T. Lumbar stabilization: core concepts and current literature, Part 1. Am J Phys Med Rehabil. 2005;84(6):473-80.

51. Larkey L, Jahnke R, Etnier J, Gonzalez J. Meditative movement as a category of exercise: implications for research. J Phys Act Health. 2009;6:230-8.

52. Phattharasupharerk S, Purepong N, Eksakulkla S, Siriphorn A. Effects of Qigong practice in office workers with chronic non-specific low back pain: a randomized control trial. J Bodyw Mov Ther. $2019 ; 23(2): 375-81$.

53. Zou L, Zhang Y, Yang L, et al. Are mindful exercises safe and beneficial for treating chronic lower back pain? A systematic review and meta-analysis of randomized controlled trials. J Clin Med. 2019;8(5): 628.

54. Zhang Y, Loprinzi PD, Yang L, Liu J, Liu S, Zou L. The beneficial effects of traditional Chinese exercises for adults with low back pain: a meta-analysis of randomized controlled trials. Medicina (Kaunas, Lithuania). 2019;55(5):118.

55. Wieland LS, Skoetz N, Pilkington K, Vempati R, D'Adamo CR, Berman BM. Yoga treatment for chronic non-specific low back pain. Cochrane Database Syst Rev. 2017;1:CD010671.

56. Li H, Ge D, Liu S, et al. Baduanjin exercise for low back pain: a systematic review and meta-analysis. Complement Ther Med. 2019;43:109-16.
57. Schuller W, Ostelo R, Rohrich DC, Apeldoorn AT, de Vet HCW. Physicians using spinal manipulative treatment in The Netherlands: a description of their characteristics and their patients. BMC Musculoskelet Disord. 2017;18(1):512.

58. Groot D, van Hooff ML, Kroeze RJ, et al. Long-term results of an intensive cognitive behavioral pain management program for patients with chronic low back pain: a concise report of an extended cohort with a minimum of 5-year follow-up. Eur Spine J. 2019;28(7):1579-85.

59. van Hooff ML, Ter Avest W, Horsting PP, et al. A short, intensive cognitive behavioral pain management program reduces health-care use in patients with chronic low back pain: two-year follow-up results of a prospective cohort. Eur Spine J. 2012;21(7):1257-64.

60. Higgins DM, LaChappelle KM, Serowik KL, Driscoll MA, Lee A, Heapy AA. Predictors of participation in a nonpharmacological intervention for chronic back pain. Pain Med (Malden, Mass). 2018;19(suppl_1):S76-83.

61. Hajihasani A, Rouhani M, Salavati M, Hedayati R, Kahlaee AH. The influence of cognitive behavioral therapy on pain, quality of life, and depression in patients receiving physical therapy for chronic low back pain: a systematic review. PM R J Injury Funct Rehabil. 2019;11(2):167-76.

62. Ostelo RW, van Tulder MW, Vlaeyen JW, Linton SJ, Morley SJ, Assendelft WJ. Behavioural treatment for chronic low-back pain. Cochrane Database Syst Rev. 2005;1:CD002014.

63. Henschke N, Ostelo RW, van Tulder MW, et al. Behavioural treatment for chronic low-back pain. Cochrane Database Syst Rev. 2010;7:CD002014.

64. Kamper SJ, Apeldoorn AT, Chiarotto A, et al. Multidisciplinary biopsychosocial rehabilitation for chronic low back pain: Cochrane systematic review and meta-analysis. BMJ (Clin Res Ed). 2015;350: h444.

65. Morone NE, Greco CM, Weiner DK. Mindfulness meditation for the treatment of chronic low back pain in older adults: a randomized controlled pilot study. Pain. 2008;134(3):310-9.

66. Mateu M, Alda $\mathrm{O}$, Inda MD, et al. Randomized, controlled, crossover study of self-administered Jacobson relaxation in chronic, nonspecific, lowback pain. Altern Ther Health Med. 2018;24(6): 22-30.

67. Cambron JA, Dexheimer JM, Duarte M, Freels S. Shoe orthotics for the treatment of chronic low 
back pain: a randomized controlled trial. Arch Phys Med Rehabil. 2017;98(9):1752-62.

68. Zaina F, Poggio M, Donzelli S, Negrini S. Can bracing help adults with chronic back pain and scoliosis? Short-term results from a pilot study. Prosthet Orthot Int. 2018;42(4):410-4.

69. Boutevillain L, Bonnin A, Chabaud A, et al. Shortterm pain evolution in chronic low back pain with Modic type 1 changes treated by a lumbar rigid brace: a retrospective study. Ann Phys Rehabil Med. 2019;62(1):3-7.

70. Phaner V, Fayolle-Minon I, Lequang B, ValayerChaleat E, Calmels P. Are there indications (other than scoliosis) for rigid orthopaedic brace treatment in chronic, mechanical low back pain? Ann Phys Rehabil Med. 2009;52(5):382-93.

71. French SD, Cameron M, Walker BF, Reggars JW, Esterman AJ. A Cochrane review of superficial heat or cold for low back pain. Spine. 2006;31(9): 998-1006.

72. Lee JH. The short-term effectiveness of balance taping on acute nonspecific low-back pain: a case report. Medicine. 2017;96(51):e9304.

73. Al-Shareef AT, Omar MT, Ibrahim AH. Effect of Kinesio taping on pain and functional disability in chronic nonspecific low back pain: a randomized clinical trial. Spine. 2016;41(14):E821-8.

74. Nelson NL. Kinesio taping for chronic low back pain: a systematic review. J Bodyw Mov Ther. 2016;20(3):672-81.
75. Traeger AC, Lee $H$, Hubscher $M$, et al. Effect of intensive patient education vs placebo patient education on outcomes in patients with acute low back pain: a randomized clinical trial. JAMA Neurol. 2018;76:161-9.

76. Wegner I, Widyahening IS, van Tulder MW, et al. Traction for low-back pain with or without sciatica. Cochrane Database Syst Rev. 2013;8:CD003010.

77. Eklund A, De Carvalho D, Page I, et al. Expectations influence treatment outcomes in patients with low back pain. A secondary analysis of data from a randomized clinical trial. Eur J Pain (London, England). 2019.

78. van Erp RMA, Huijnen IPJ, Jakobs MLG, Kleijnen J, Smeets R. Effectiveness of primary care interventions using a biopsychosocial approach in chronic low back pain: a systematic review. Pain Pract. 2019;19(2):224-41.

79. Cowell I, O'Sullivan P, O'Sullivan K, Poyton R, McGregor A, Murtagh G. Perceptions of physiotherapists towards the management of non-specific chronic low back pain from a biopsychosocial perspective: a qualitative study. Musculoskelet Sci Pract. 2018;38:113-9.

80. Rihn JA, Radcliff K, Norvell DC, et al. Comparative effectiveness of treatments for chronic low back pain: a multiple treatment comparison analysis. Clin Spine Surg. 2017;30(5):204-25.

81. Hellum C, Johnsen LG, Storheim K, et al. Surgery with disc prosthesis versus rehabilitation in patients with low back pain and degenerative disc: two-year follow-up of randomised study. BMJ (Clin Res Ed). 2011;342:d2786. 